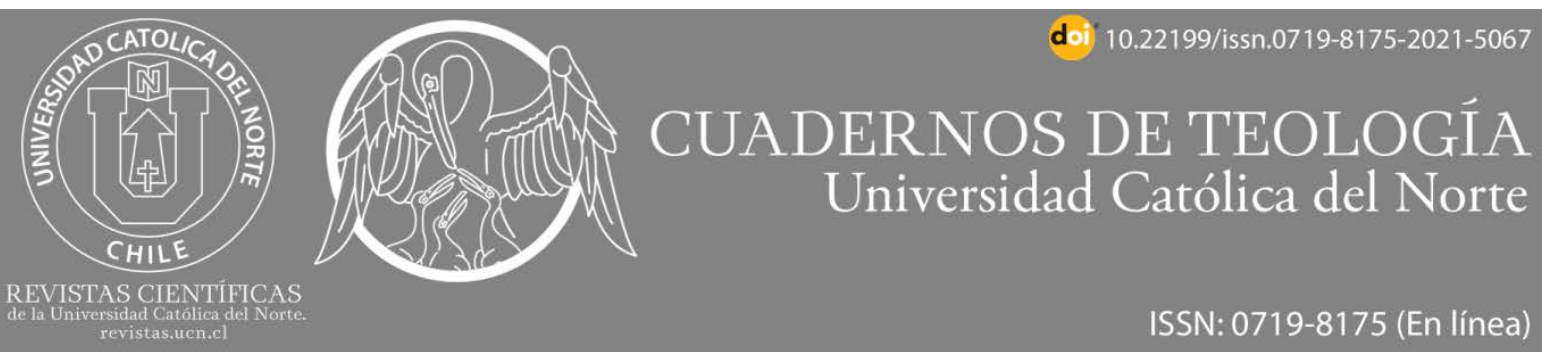

\title{
"Ser mano de niño afirmada en Ti": la fragilidad de la persona humana en la poesía religiosa de Esteban Gumucio SSCC.
}

\section{"To be a child's hand affirmed in You": the human person fragility in the religious poetry of Esteban Gumucio SSCC.}

\author{
María Ignacia Manterola Domínguez 1 D orcid.org/0000-0003-4508-495X \\ 'Pontificia Universidad Católica de Chile, Santiago, Chile. Estudiante de Licenciatura en Letras Hispánicas. \\ mimanterola@uc.cl

\section{(cc) BY}

\begin{abstract}
Resumen:
Se analizan tres poemas de Esteban Gumucio SSCC: "Quiero ser tu amigo Jesucristo", "Canto de María al anuncio del Ángel" y "No sé cómo orar". Los poemas conciernen a la pregunta acerca del modo en que se define la persona humana y su proyección de sentido a partir del contacto personal con Dios, y ponen de manifiesto una poética que concibe, al individuo, como un ser frágil que es amparado en la alteridad divina. El hablante lírico experimenta el contacto con un Dios amoroso, por el que da un salto de incertidumbre debido a su frágil entendimiento de lo trascendente. Esto se evidencia tanto en el modo de enunciar como en el contenido semántico. A partir de ahí, la persona humana encuentra un sentido existencial al unirse a la voluntad del Dios que lo sostiene, lo que significa el riesgo de confiar su fragilidad a un otro trascendente.

Palabras Clave: fragilidad humana; alteridad; trascendencia; poesía religiosa chilena.
\end{abstract}

\section{Abstract:}

Three poems by Esteban Gumucio SSCC are analyzed: "Quiero ser tu amigo Jesucristo", "Canto de María al anuncio del Ángel" and "No sé cómo orar". The poems concern the question about the way in which the human person is defined and its projection of meaning from personal contact with God, and they reveal a poetics that conceives the individual as a fragile being that is protected in divine otherness. The lyrical speaker experiences contact with a loving God, whereby he takes a leap of uncertainty due to his fragile understanding of the transcendent. This is evidenced both in the way of enunciating and in the semantic content. From there, the human person finds an existential meaning by joining the will of the God who sustains him, which means the risk of entrusting his fragility to a transcendent other.

Keywords: human fragility, otherness; transcendence; religious poetry, Chilean. 


\section{Introducción}

La poesía religiosa chilena, en el siglo XX, fue abundante y gozó de positiva valoración crítica. Poetas como José Miguel Ibáñez Langlois, Miguel Arteche y Rosa Cruchaga aportaron cuantiosamente a tal archivo. Esta investigación quisiera ser una oportunidad para analizar la obra de Esteban Gumucio (1914 - 2001), sacerdote y poeta autor de un grueso corpus que puede sumarse también a dichas filas. Es interesante constatar el escaso o nulo estudio académico que se ha hecho a este escritor, paradójicamente muy popular en la Iglesia chilena como sacerdote, pero también como poeta. El estudio académico de la poesía de Gumucio es una vía casi inexplorada, que puede hacer un importante aporte al archivo de poesía religiosa que existe en Chile.

Ahora bien, el tema de este estudio se centra en la experiencia individual interpersonal de la persona humana con Dios, desde la cual se despliegan una serie de conceptos fundamentales que definen lo propiamente humano. La pregunta acerca de quién es el Hombre y cuál es el sentido de su existencia ha sido, a menudo, intentada de responder desde distintas ramas del humanismo. En esta línea, no supone ninguna novedad intentar encontrar la identidad de la persona humana con relación a un ser trascendente que dé sentido a la vida.

Sin embargo, la poesía de Gumucio es un aporte para esta problemática desde distintos puntos de vista. En primer lugar, los acercamientos literarios suelen dar espacio a un tipo de pensamiento, intuitivo y experiencial, que se escapa de los parámetros del racionalismo, predominante en las humanidades modernas. Por otro lado, Gumucio elabora una poesía que tiene algunos rasgos característicos en los cuales se detendrá el análisis: la actitud, el lenguaje y la estructura de los poemas son signos del modo conversacional que establece el hablante con la persona divina. Esto supone un punto de entrada diferente al problema del ser humano, pues permite analizar la experiencia personal y específica de la persona frente al Dios, en el que busca identidad y sentido. Esta lírica que se construye en diálogo interior es posiblemente un camino para liberarse de los afanes de exposición ideológica o entendimiento cabal que pueda existir en otras literaturas, ya que reconoce y se inclina ante un pensar ajeno que supera el propio. Por último, el perfil poético de Esteban Gumucio constituye una riqueza literaria por su singularidad: su percepción de la persona humana se posiciona desde su ser chileno, ajeno a los círculos intelectuales que existían en el país; y sacerdote católico cuyo quehacer poético está al servicio de la experiencia religiosa.

El trabajo estudiará tres poemas pertenecientes a la antología póstuma del autor, Poemas (2005), editada por Natacha Pavlovic y presentada por Eduardo Pérez-Cotapos SSCC. De las piezas a analizar, dos de ellas habían sido publicadas anteriormente y otra corresponde a un texto inédito: "Quiero ser tu amigo, Jesucristo" (Cantos desde el centro), "Canto de María al anuncio del ángel" (Escritos) y "No sé cómo orar" (inédito). Cabe mencionar la singularidad del poema "Canto de María al 
anuncio del ángel" dentro del corpus, en que el poeta se sitúa desde una voz ajena, la de la Virgen María. Este poema es relevante para la investigación, porque allí se revela una experiencia humana marcada por la incertidumbre y el riesgo muy valiosa para el estudio.

Los poemas fueron escogidos por ser una respuesta a la problemática acerca del delineamiento de la persona humana al contacto con Dios en la poesía de Gumucio. En ellos lo humano, representado en el hablante lírico, hace un reconocimiento de la persona divina, y pone en marcha una poética que da pistas fundamentales de la autopercepción del hablante lírico en relación con el Otro divino.

A partir de este corpus literario seleccionado de Esteban Gumucio SS.CC, se buscará responder a la siguiente pregunta: ¿de qué modo se define la persona humana y su proyección de sentido a partir del contacto personal con Dios?

En la poesía de Esteban Gumucio SS.CC, la persona humana es caracterizada como un ser eminentemente frágil en su estructura. Esta fragilidad se manifiesta principalmente en la incertidumbre frente a lo trascendente y en su incapacidad para expresar de forma verbal lo inefable del misterio divino. El hablante lírico instala un lugar espiritual de profunda intimidad donde la persona humana experimenta el contacto con un Dios amoroso. Es aquí donde la percepción de la fragilidad cambia al verse complementada por la presencia de un Otro providente, que no elimina la fragilidad humana, pero sí la sostiene de forma incondicional. A partir de este fenómeno, el hombre encuentra un sentido al unirse a la voluntad del Dios que lo sostiene, aunque signifique asumir riesgos que pongan constantemente a prueba su fragilidad. Para expresar este juego de alteridades, el hablante lírico utiliza una serie de recursos literarios que se manifiestan principalmente en el modo enunciativo, la elección léxica a nivel semántico, y el recorrido que trazan los poemas.

\section{Estado de la cuestión}

Acerca de la persona y sentido en la relación personal con Dios, en la poesía de Esteban Gumucio SSCC, resulta difícil establecer un estado de la cuestión contundente. Existe un estudio anterior muy escaso de la poesía del autor a nivel literario académico, por lo que podría decirse que se trata prácticamente de un territorio inexplorado o solo considerado desde la distancia. Bajo estas condiciones, se ha optado por ampliar la recopilación en dos ejes distintos: estado de la cuestión en Gumucio y comentarios no académicos a la poesía de Gumucio.

El único estudio académico literario publicado, acerca de la poesía de Gumucio, es de Roberto Onell: "Poemas. Esteban Gumucio SSCC". Se trata de una reseña breve del poemario en el que se encuentra el corpus de esta investigación. A pesar de que no comenta los mismos poemas que en esta ocasión, es posible rescatar dos ideas que también son aplicables a la temática actual. 
Por un lado, se reconoce la experiencia de incertidumbre humana en los poemas al señalar que "el poeta va de cara al misterio y atento a la inminencia de un rostro" (2010, p.137). Por otro lado, al decir que en Gumucio "el poema es comunicación" (2010, p.137), se reafirma el carácter conversacional que se analizará en este estudio.

Ahora bien, existe un artículo no publicado de Jaime Blume y Felipe Espinoza (2021), compartido en una comunicación personal a la autora: "Una fe, dos miradas: los discursos poéticos de José Miguel Ibáñez y Esteban Gumucio". En este artículo se sugiere una lectura de la poesía de ambos sacerdotes desde sus biografías. Sobre Gumucio, podemos encontrar un claro énfasis en la preocupación social de su poesía antes que en la experiencia interior con Dios que ésta presenta. Aun así, es valioso el recorrido que el artículo hace por el poema "Sigo a un hombre llamado Jesús". Los autores afirman que el poema "resulta un viaje a lo más profundamente cristiano y señala en qué consiste dicha experiencia" (2021, p.13). Ese análisis vital del cristianismo, que enuncia el hablante lírico, es el punto de convergencia con la nueva investigación.

Esos dos documentos son los estudios literarios que, hasta hoy, existen de Gumucio. Sin embargo, hay también una serie de comentarios no académicos a su poesía que dan pistas para la orientación de la temática a tratar en esta investigación.

Uno de los estudios más importantes, que se han hecho de la persona de Gumucio, es la tesis de Matías Valenzuela: Esteban Gumucio Vives sscc. Espiritualidad de un religioso sacerdote. Por tratarse de una tesis académica de teología, el comentario no es estrictamente literario y se interesa más bien en Gumucio como poeta, no en sus escritos en particular. Sin embargo, es relevante la siguiente idea de Valenzuela respecto a la poesía de Gumucio: "Resuenan en él las palabras de Jesús que lleno de alegría y de la fuerza del Espíritu aclama, te alabo Padre, porque has revelado estas cosas a los pequeños (Cf. LC 10,21)" (2013, p.155). Aquella evidente pequeñez, o infancia espiritual, forma parte de lo que ahora se quiere estudiar detenidamente en el concepto de fragilidad.

En segundo lugar, es posible vislumbrar un aporte para el estudio en la entrevista de Paz Escárate Cortés: "Entrevista con Esteban Gumucio, ss.cc. Bienaventurados los mansos". Acá Gumucio se refiere a su experimentación personal de Dios y cómo sus propias limitaciones han jugado un rol fundamental para entenderlo: "El límite del ser humano es parte de su ser. Dios me hizo limitado, entonces como una flor es hermosa por sus límites, también el contorno de la vida humana es hermoso, es Dios quien lo ha querido así" (1999, p.39). Por tanto, el mismo autor pareciera haber tenido una consciencia de la fragilidad como un elemento fundamental para la relación con la persona divina. Sin duda, esta no es una afirmación concluyente acerca de la realidad poética del autor, pero sí es una conformación de que el problema del estudio es adecuado.

En conclusión, resulta evidente que la poesía de Gumucio no ha sido investigada detenidamente; al menos no desde la academia literaria. Las críticas literarias que podemos 
encontrar de él se reducen a una única reseña, y a una investigación que no ha sido publicada. Además, esta última, por su objetivo de reseñar y no investigativo, es una mirada detenida antes que una crítica o análisis profundo. Por otro lado, los acercamientos no académicos a la poesía de Gumucio son de ayuda para considerar, entre otras cosas, la percepción que tienen los lectores. Sin duda son una pista de elementos que vale la pena estudiar académicamente.

\section{Análisis literario}

\section{1. "Quiero ser tu amigo Jesucristo"}

Eres mi futuro y mi presente, Jesucristo; mi horizonte sobre llanuras anheladas.

Desde ayer eres mi amigo:

desde siempre.

En la noche extiendo mi mano adolescente,

toco tus ojos, adivino tu mirada.

Eres canto, rocío, llamada

que despierta lo mejor de mi secreto.

Eres la fuerza de ser libre;

contigo voy clavando pasos monte arriba,

y cuando todo mi contorno se estremece

eres Tú el amigo, y permaneces.

Una música humana, cuajada de esperanza, Jesucristo.

Un fuego encendido y lumbre nueva, Jesucristo.

Eres pan de mis mañanas,

eres pórtico y camino,

eres sol de mediodía y descanso que renueva.

Contigo es bueno sentir la juventud,

cantar el mismo canto,

correr a los picachos, bajar a las audacias.

Quiero oír tu voz de siempre,

Amigo, Señor y compañero,

y encontrarme, tal vez, sin bolsa ni bastón,

durmiendo por Ti al frescor de las estrellas.

Contigo quiero descubrir las cosas bellas:

vivir la transparencia, la verdad.

Quedarme a tus pies para guardar tu sueño

o salir a tus urgencias, al menor signo de tu mano.

Dame ser un corazón inquieto

al atisbo de pájaros y brisas y ventanas recién abiertas.

Quiero ser ojos que lo miren todo desde adentro,

desde tu presencia;

y quiero ser mano de niño afirmada en $\mathrm{Ti}$,

sin dolor, sencilla, sin mentira;

y que me queden cortas las palabras

cuando hable de Ti;

que me quede chico el corazón,

incapaz de mis anhelos;

que me quede estrecho el mismo cielo,

cuando te busque a Ti.

Yo quiero ser tu amigo, Jesucristo,

yo quiero ser tu amigo:

que nunca jamás me doblegue la bajeza;

que no me venza la mentira y la tristeza.

Quiero ser chispa de tu fuego

$y$ gota de tu fuente 


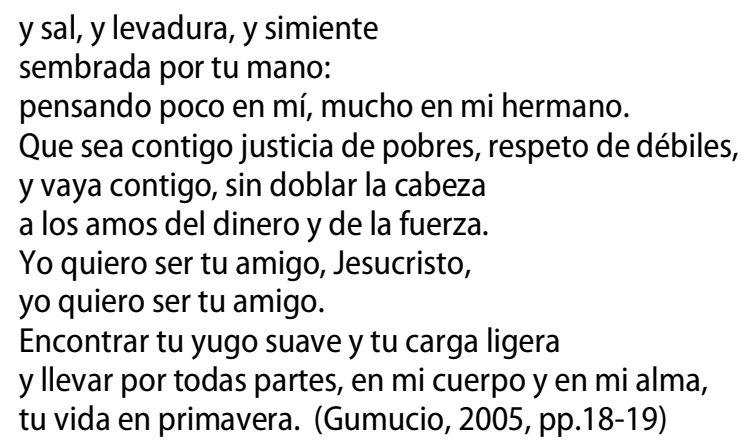

Uno de los rasgos más importantes de este poema es el estilo enunciativo. Situado entre los difusos límites de la poesía y la plegaria, el hablante se dirige en segunda persona a Dios en términos formales poco canónicos. Predominan los versos largos que no se atienen a una métrica definida, y que riman solo ocasionalmente. Si bien se utilizan ciertas metáforas que no calzan del todo en una comunicación coloquial - entre otros casos, el de "mi horizonte sobre llanuras anheladas" -, el hablante lírico maneja un léxico sencillo que es bastante diáfano. Incluso a lo largo del texto aparecen rasgos propios de la oralidad, como lo son el reiterado conector "y" ("y sal, y levadura, y simiente"), o el uso de la expresión vacilante "tal vez". Son todas estas características las que llevan a pensar en un tono conversacional del hablante lírico que, se verá más adelante, define el corpus seleccionado en esta investigación.

La dinámica conversacional del poema es significativa. Se trata de un estilo que contribuye a la consigna principal de toda la enunciación, la relación de amistad con Jesucristo. La persona en contacto con Dios se sitúa en un contexto de profunda intimidad que da lugar a un diálogo despojado de grandilocuencias. Siguiendo esta línea, aparece un rasgo fundamental para entender el tipo de fragilidad que encarna el hablante lírico como humano frente a lo divino: la conversación siempre está en desarrollo; su espontaneidad permite que el mensaje, no absoluto desde el principio, se vaya esclareciendo mientras la enunciación avanza. Además, la conversación deja espacio a lo que el interlocutor tenga que decir, por lo que no está acabada en sí misma. El hablante lírico, por tanto, deja en evidencia la fragilidad de no poseer la verdad absoluta del poema. Su palabra está abierta a la complementación con la palabra de Dios.

Ahora bien, para entender la relación del hombre con Dios en el poema es necesario hacer una caracterización de la persona divina tal y como ahí aparece. El apelativo "Jesucristo", nominalización elegida para Dios en ventaja a tantas otras posibles, es bastante sugerente. Esta palabra hace referencia a la persona del Hijo dentro de la Santísima Trinidad, aquel que tomó condición humana para redimir a la Humanidad. De parte del autor, parece una opción premeditada la de utilizar de forma conjunta "Jesús", que hace hincapié en el sujeto humano que vivió en Nazaret y que existió según la naturaleza; y el de "Cristo", nombre que se refiere particularmente al Mesías, el Dios Salvador. Ambas realidades aparecen con igual énfasis en la caracterización de Dios; por un lado se trata de una persona que vive plenamente el ciclo humano - "Quedarme a tus pies para guardar tu 
sueño" -, pero que también redime las miserias del mundo: "Que sea contigo justicia de pobres, respeto de débiles". En síntesis, el nombre de Jesucristo, repetido en cinco ocasiones dentro del poema, remite al Sujeto que abraza la fragilidad humana al punto de adquirirla para sí mismo, pero que a la vez sana dicha fragilidad por medio de la redención. Por lo tanto, el deseo de amistad del hablante lírico puede leerse como el anhelo de aceptar su propia condición en la humanidad de Jesús -“Cuando todo mi contorno se estremece / eres tú el amigo, y permaneces" -, pero también de proyectarla más allá de sus límites por medio de la redención en Cristo: "y vaya contigo, sin doblar la cabeza / a los amos del dinero y de la fuerza".

El paso que hace la fragilidad hacia la redención está ligado estrechamente al paso de la incertidumbre al riesgo que estructura el poema. La primera estrofa trata la experiencia de la visión reducida de la presencia sobrenatural de Dios en la vida propia. La imagen de "mi horizonte sobre llanuras anheladas" pone de manifiesto que Jesucristo se encuentra para el hablante en la cúspide de los valores, pero a la vez, lejos de sí. Poco más adelante aparecen los versos "En la noche extiendo mi mano adolescente / toco tus ojos, adivino tu mirada". La lejanía del horizonte y la intuición, en medio de la oscuridad, generan un conocimiento de Dios que no llega a ser ni racionalmente empírico, ni logra penetrar el misterio divino, como sí lo hace la poesía religiosa mística (por ejemplo, Teresa de Ávila y Juan de la Cruz). Es que acá el hablante lírico no es ni el sujeto positivista de la modernidad, ni pertenece al número de los que tienen el don místico. Representando a la gran mayoría de los creyentes de las últimas décadas, Gumucio elabora un hablante que no tiene certezas empíricas, pero percibe a Dios escondido en la vida natural y también a lo largo de su propia historia: "Desde ayer eres mi amigo: / desde siempre". De ahí nace la larga caracterización de Jesucristo utilizando metáforas de la naturaleza y la cotidianidad: "canto, rocío, llamada", "música humana", "fuego encendido", "pan de mis mañanas", "pórtico y camino", "sol de mediodía y descanso que renueva". La incertidumbre, que en este caso es la limitación humana para sumergirse con entendimiento cabal en las verdades sobrenaturales, es entonces desafiada por el riesgo de creer en Jesucristo.

Ya, a partir del final de la tercera estrofa, comienza a manifestarse la proyección de sentido del hablante lírico según el arriesgarse en Cristo. Los versos "y encontrarme, tal vez, sin bolsa ni bastón / durmiendo por Ti al frescor de las estrellas" son imagen clara de la actitud que tomará la fragilidad humana en el resto de los ideales enumerados en el poema. La carencia de bolsa, bastón y techo es osada, precisamente porque simboliza la renuncia a todo tipo de suplementos con las que el mundo secular ha pretendido contrarrestar su fragilidad: la bolsa como los bienes materiales, el bastón como la autosuficiencia, y el techo como la aparente estabilidad de la civilización moderna. La nueva lógica, del salto de fe en Jesucristo, exige la confianza total en que solo puede ser Dios quien sostenga la propia limitación. Aquí viene a colación uno de los versos más decidores del poema: "Y quiero ser mano de niño afirmada en Ti". El mensaje es profundo: el sujeto prescinde de 
seguridades terrenales no porque Dios lo convierta en un superhombre heroico que está exento de fragilidad, sino porque la fe lo dota de una confianza heroica para arriesgar dicha fragilidad.

Es necesario detenerse un momento en la idea de "ser mano de niño afirmada en Ti". La opción por autodefinirse como niño es significativa, tomando en cuenta que todo el poema está marcado por la idea de amistad. La reciprocidad desinteresada que subyace a la amistad presupone a dos sujetos que se encuentran, de una u otra forma, en igualdad de condiciones. Por lo tanto, la actitud más adecuada al tono de la enunciación sería la de una relación solidaria equitativa; sin embargo, existe una decisión en este punto por establecer la primacía de una relación filial. Aquí aparece con claridad que la amistad a la que se refiere el poema no se trata de un pacto de simpatía entre dos partes equitativas. El ser amigo de Jesucristo es sumergirse en la intimidad vital del Amor con Él; de ahí los versos "Quiero ser los ojos que miren todo desde dentro / desde tu presencia". Sin embargo, el hablante sabe que no está en igualdad de condiciones con Jesucristo, que es Dios omnipotente: "Quiero ser chispa de tu fuego / y gota de tu fuente". La proyección de su fragilidad es apenas una fracción dentro del ideal de Jesús, pero es uniéndose a la grandeza de Él donde encuentra sentido.

En los otros poemas aparecerá reiteradamente el léxico de la filialidad y la infancia para autodefinirse. De momento, cabe destacar también la idea de la "mano adolescente" al principio del poema, que contribuye a la percepción de un sujeto que aún es vulnerable, en contraposición a la resolución del adulto.

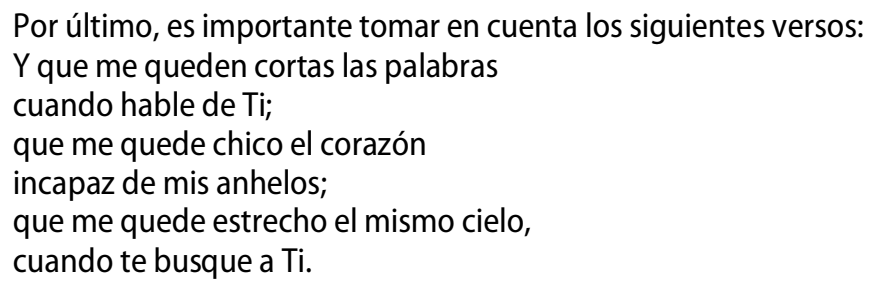

En términos de fragilidad, este fragmento es de gran riqueza analítica. La proyección ideal del hablante lírico no solo acepta su fragilidad, sino que la valoriza como un instrumento para expresar la intensidad del amor a Dios. Podría decirse que el hablante incluso desea ser incapaz de estar a la altura del amigo Jesucristo, a fin de que así se manifieste la grandeza de este. En esta lógica de la fragilidad como un valor, es posible ver que los antivalores del poema son precisamente los que niegan la fragilidad afirmando la autosuficiencia, como los son "los amos del dinero y de la fuerza". Podría decirse que también "la mentira y la tristeza" entran en esta lógica, si se piensa la tristeza como la desesperanza en que la redención de Dios sanará las miserias del hombre. 


\section{2. "Canto de María al anuncio del Ấngel"}

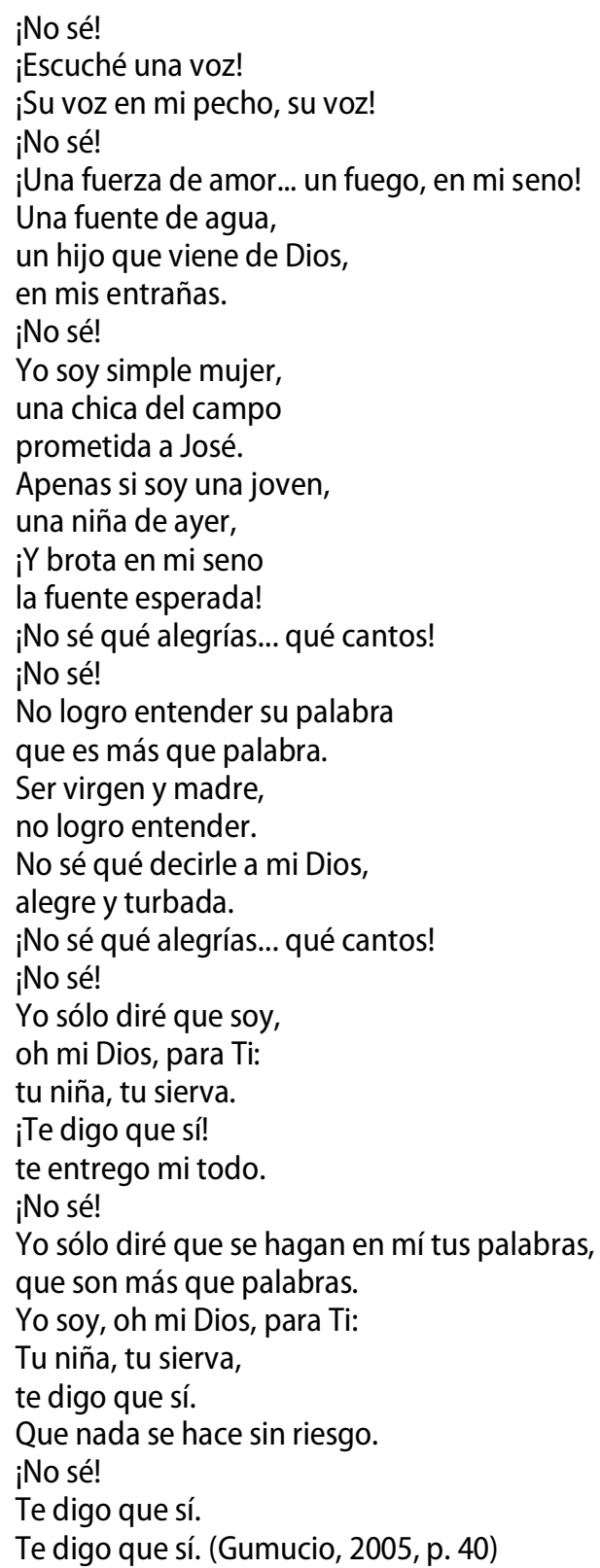

Este poema presenta la particularidad de que el hablante lírico es una mujer en específico, la Virgen María, en una situación histórica determinada: el anuncio del Ángel para ser la madre de Dios. De esto se deduce que el poeta sin duda alguna ha debido ponerse en un rol de alteridad, situación que no es del todo unívoca en "Quiero ser tu amigo Jesucristo" o en "No sé cómo orar" (Además, los lectores suelen identificar con los rasgos del autor a aquellos hablantes líricos que no evidencian un perfil determinado). Sin embargo, que la experiencia de fragilidad también sea lo primordial de la Madre de Dios en este poema permite comprobar que, en la poesía de Gumucio, la fragilidad no se reduce a un solo sujeto o a un tipo de persona con ciertos rasgos psicológicos, sino que es una vivencia común en la humanidad. La fragilidad también se encuentra en María, la joven mujer de hace veinte siglos que, por lo demás, según el credo católico es madre de la Iglesia. Esto quiere decir que lo que ocurre a ella es, en un sentido místico y sobrenatural, lo que ocurre a toda la comunidad. 
Ahora bien, la dinámica conversacional también cumple un rol fundamental en este análisis, pero operando de un modo diferente. Aunque hasta el quinto "iNo sé!" (verso 26) se enuncia a Dios en tercera persona, de todos modos pareciese haber un intento de formular la experiencia propia para un interlocutor, tal como ocurre en las entrevistas. El inicio del poema grafica muy bien este fenómeno: “¡No sé! / ¡Escuché una voz!". Luego del verso 26 el interlocutor se vuelve Dios mismo: "Yo sólo diré que soy, / oh mi Dios, para Ti".

Otro rasgo conversacional es el flujo continuo y no organizado que significa el hecho de que todo el poema sea una sola estrofa, o bien el vocabulario sencillo y muchas veces repetido que allí se presenta. Ya fue mencionado, anteriormente, por qué el carácter conversacional de la poesía de Gumucio es reflejo de la fragilidad del hablante, pero en este caso la percepción de fragilidad se acrecienta por una especie de deficiencia enunciativa que va más allá de una conversación común; diríase que en este caso el poema es casi un balbuceo. Los versos son de métrica corta y hay muchas expresiones que se repiten más de una vez. La vaga expresión "No sé" aparece diez veces, hay cuatro "Te digo que si", y están repetidas las unidades "¡No sé qué alegrías... qué cantos!", "no logro entender", y "soy, oh mi Dios, para Ti; / tu niña, tu sierva / te digo que sí". La hablante experimenta la incapacidad de formular con claridad el desconcertante misterio de la encarnación.

Esta limitación de la comunicación humana, ante la grandeza de Dios, se encuentra en estrecha relación con el concepto de incertidumbre. La hablante no puede formular el misterio en parte porque no encuentra las palabras, pero también porque no tiene claridad absoluta de qué está sucediendo: "Ser virgen y madre / no logro entender". Las repeticiones del "No sé" a lo largo de la enunciación son pequeñas pausas en el esfuerzo comunicativo a fin de dejar ver la limitación que a pesar de todo lleva en sí. No obstante, la incertidumbre aquí tiene un matiz alegre que valoriza positivamente la propia fragilidad del entendimiento; en voz del mismo poema, el temple de ánimo ante el misterio es el de estar "alegre y turbada". Así también lo demuestra el verso repetido: "¡No sé qué alegrías... qué cantos!". Si se piensa que la incertidumbre no es desoladora, pues existe consciencia de que se trata de "un hijo que viene de Dios", es posible sostener que es la confianza en Dios la que valoriza la fragilidad del hablante.

Desde ese pensamiento se entiende la aceptación del riesgo que, paulatinamente, va guiando el poema, y que aparece como una de las temáticas explícitas: "Que nada se hace sin riesgo". A diferencia de "Quiero ser tu amigo Jesucristo", en "Canto de María al anuncio del Ángel" la proyección de la fragilidad del yo, no necesita sobreabundar en metáforas, pues es una y concreta: asumir el misterio de la encarnación en el propio ser:

Yo sólo diré que soy,

oh mi Dios, para Ti:

tu niña, tu sierva.

¡Te digo que sí! 
En efecto, en el poema el riesgo que toma la hablante es la libre apertura a Dios que se reitera en cada "Te digo que sí"; sin embargo, no es ella quien realiza la encarnación misma. Por ello se utiliza una voz impersonal a la hora de describir el proceso: " $\mathrm{j} Y$ brota en mi seno / la fuente esperada!". La palabra "brotar", por lo demás, da una idea de espontaneidad sin artificio. Según esto se explica también que el verso "¡Una fuerza de amor... un fuego, en mi seno!" no tenga verbo, pues no hay claridad del proceso como tal. De este discurso se subentiende que la encarnación es fruto de la acción sobrenatural de Dios. Este pensamiento es sumamente interesante en términos de fragilidad humana, pues grafica con claridad el modo de íntima complementación entre la divinidad y la creatura; la fuerza viene de Dios, y el individuo la adquiere mediante el libre servicio a Él. De ahí se concibe positivamente la imagen de la "sierva", pues el servicio es también ganancia para aquél que lo realiza.

Ahora bien, es necesario destacar lo que dice el poema acerca de la autopercepción de la hablante:

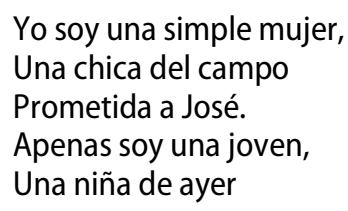

Todo el léxico de esta sección es una prueba de la fragilidad con que la hablante se concibe a sí misma. Al ser mujer dentro de la masculinizada cultura judía del siglo primero (esta idea, si bien no aparece explícitamente en el poema, aparece implícitamente con el hecho de evocar el personaje histórico de María de Nazaret), se suma el ser una "niña" de edad reducida, además de ser "una chica de campo" aislada de la prosperidad cívica de la urbe. Palabras como "apenas" y "simple" reafirman la actitud de estatus bajo. El puesto de vulnerabilidad que ocupa la hablante quiere contrastar con la grandeza del don de Dios recibido íntimamente, y que la hace repensar su condición de fragilidad. Es por esto que, la hablante, varía su discurso de "una niña de ayer" a "Yo soy, oh mi Dios, para Ti: / tu niña, tu sierva". La condición de infancia, subestimada a lo largo de la historia (que podría ser una explicación del sentido de "ayer" en el poema), encuentra valor al unirse filialmente a Dios.

\section{3. "No sé cómo orar"}

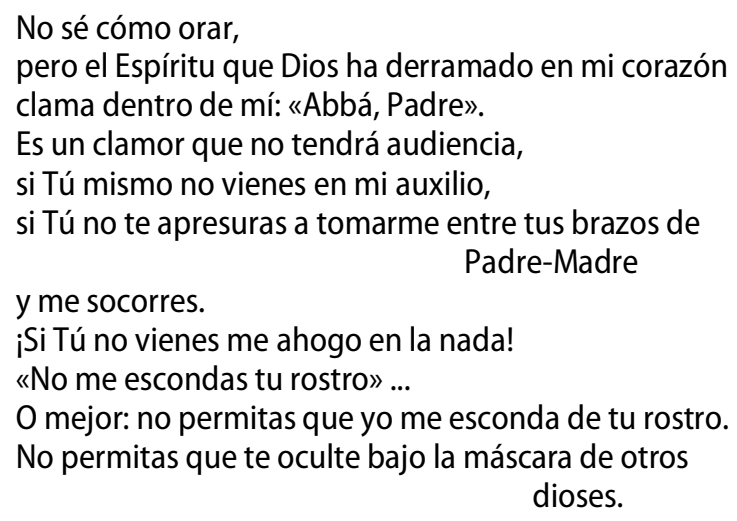


«Inclina tu oído hacia mí»,

mi voz es tan leve como la de un niño que comienza a

balbucear...

Tú te inclinas,

te abajas hasta el nivel de mi boca casi muda...

Me escuchas enseguida, cuando te invoco.

¡Te basta un susurro y ya estás aquí!

Te digo: «mis días se desvanecen como humo», pero estando Tú inclinado sobre mí, cercano a mí, te digo esas palabras sin nostalgia,

con cierto humor alegre.

No, no soy como «lechuza en la estepa,

ni como búho entre ruinas».

Estoy, más bien, como un niño que despierta de una pesadilla

y se encuentra con el rostro del padre y de la madre.

En el centro de mi ser oigo la voz:

«Tú eres mi hijo amado en quien me complazco».

Es la misma voz que dio vida al primer Adán;

la misma voz que habló a Jesús, segundo Adán.

Es la voz que habla a todos los hijos en el Hijo.

La voz que hace brillar la luz en las tinieblas.

Yo conozco esa voz: me habló en el pasado,

desde niño pequeño, la voz que hablaba a mis padres, la voz del amor de Dios, que no deja de llamar.

Desde toda la eternidad su voz me llama y me da vida.

Él está en mí, en el centro de mi ser,

en los profundos cimientos de mi Espíritu.

No tengo que temer: «aunque pase por un valle tenebroso, ningún mal temeré».

Mi mano, en tu mano, Padre,

escuchando a Jesús en mi auténtica morada,

en la casa de Dios, en mi corazón de bautizado.

«Señor, escucha mi oración.

Que mi grito llegue hasta Ti»

¿Qué pasa?... ¡Parece que no brota ningún grito

desde mi alma seca y sedienta!

¡No parece ser oración lo que mis labios dicen!

¿Será un rezo más?

¿Una palabra rutinaria?

Tú me invitas a descubrir el grito del alma.

Es casi un murmullo callado que se filtra.

Me dices en lo secreto: Yo sé que me llamas,

aunque tu corazón parece estar dormido,

escucho la oración que no dices.

Tu Espíritu, Señor, la inspira en el recinto del silencio, con gemidos inenarrables.

Tú me dices: Recuerda, eres mi hijo. Te conozco.

También cuando estás dormido, te amo.

«Que mi grito llegue hasta Ti, Señor...

No me escondas tu rostro».

Me invitas a reconocer la voz que viene desde las

entrañas.

Tú lo escuchas, Padre: es el clamor de Jesucristo, el Hijo.

Sólo el Espíritu me lo hace manifiesto,

cuando logra silenciar mi corazón.

Lo que hago, lo que pienso, lo que pasa... me aturden; son unos parlantes indiscretos, a todo volumen, que no dejan escuchar al amigo vecino.

Ahora, «ven en mi auxilio; 
apresúrate, Señor, a socorrerme». (Gumucio, 2005, pp.22-23)

El análisis de este poema difiere del que se ha hecho anteriormente de "Quiero ser tu amigo Jesucristo" y "Canto de María al anuncio del Ángel", pues utiliza un estilo mucho más complejo y existencialista. La dinámica conversacional, como se había descrito en los otros poemas, se puede identificar ahora solo parcialmente. Si bien conserva los rasgos más fundamentales, como la actitud apostrófica que establece un diálogo directo e íntimo con Dios, o bien una métrica larga en verso libre que recuerda a la prosa, las constantes citas bíblicas dentro del poema desencajan en el registro coloquial y espontáneo que primaba en los otros. La opción por utilizar una dinámica conversacional más docta contribuye, de cierto modo, a caracterizar al hablante lírico. En este poema el hablante saca a colación citas bíblicas sin dar cátedra a nadie más que a sí mismo. Dicho de otra forma, las citas bíblicas son una respuesta a sus propias dudas, o bien herramientas para expresar lo inefable de su alma. En este sentido, los elementos doctos del texto no contribuyen en absoluto a delinear un hablante de sabiduría maestra. Es más; si se asumen las Sagradas Escrituras bajo la autoría de Dios, quien inspiró las palabras allí escritas, es la Divinidad misma quien da una lección al hablante. Que la voz de la persona humana se deje complementar por la voz bíblica de Dios, ante la falta de recursos propios, pone de manifiesto que la conversación docta también refleja la fragilidad enunciativa del hablante.

La incertidumbre central en este poema es acerca de la eficacia de la oración como medio para conectarse con Dios, de allí el título y primer verso "No sé cómo orar". El hablante parece incapaz de acceder al diálogo con Dios por medio de la plegaria: "Es un clamor que no tendrá audiencia, / si tú mismo no vienes en mi auxilio". Esto genera una inseguridad acerca de quién se encuentra al otro lado del misterio sobrenatural: la Persona Divina, o bien la nada. De ahí que puedan identificarse claras conexiones entre el poema y el existencialismo moderno. Diríase que este hablante es el que tiene un perfil más prototípicamente moderno del corpus analizado, pues sus dudas acerca del Ser Trascendente consideran la posibilidad fatal de la vida como un sinsentido: "¡Si Tú no vienes me ahogo en la nada!". Para el hablante la idea de la inexistencia de Dios es terrible, pues no confía en que la persona humana por sí misma pueda salvarse. El hombre que tiene la fuerza de adjudicarse un sentido vital según su propia disposición resulta entonces imposible dentro de la lógica del poema.

El cambio de actitud en el hablante, desde el sinsentido a la esperanza, está relacionado con la concepción paternal de Dios, referida a la primera persona de la Santísima Trinidad:

Estoy, más bien, como un niño que despierta de una pesadilla

y se encuentra con el rostro del padre y de la madre.

A Dios Padre es a quien se apela desde el principio de la enunciación: "Pero el Espíritu que Dios ha derramado en mi corazón / clama dentro de mí: «Abbá, Padre»". La expresión "Abbá" es 
fundamental para caracterizar la paternidad de Dios dentro del poema. Se trata de la palabra hebrea que utilizaba Jesús en el Nuevo Testamento para rezar el Padrenuestro. El matiz de la palabra hace alusión a un Dios Padre amoroso sobre la imagen del dios severo del Antiguo Testamento. Esto indica, por un lado, que el hablante imita los modos de oración de Jesucristo (nuevamente, usar la palabra de Jesús para expresar lo inefable), y por otro lado, que el Dios del poema se rige por la ley fundamental del amor. Esta concepción amorosa de la persona divina es capaz de abrazar las limitaciones de la fragilidad humana, en contraposición a un dios moralista severo que exige el mérito de la creatura: "Tú me dices: Recuerda, eres mi hijo. Te conozco. / También cuando estás dormido, te amo". El dormir, que puede ser interpretado como la inacción, es merecedora del amor porque la paternidad genuina que propone el poema ama al hijo inmeritoriamente.

En esta misma línea, es relevante que -en dos ocasiones - el poema propone que Dios es padre y madre a la vez: en la metáfora del niño que despierta asustado "y se encuentra con el rostro del padre y de la madre", y en los versos "si Tú no te apresuras a tomarme entre tus brazos de / Padre-Madre". La teología de la escuela tomista sostiene que Dios es el ser mismo - Deus est ipsum ese - y en sí están la plenitud de las esencias (Meis, 2010, p.16); por tanto, abarca en sí la naturaleza femenina y masculina. Otros pensadores de esta escuela, como la filósofa y santa Edith Stein, propone incluso que lo femenino se identifica de forma especial con el Espíritu Santo (p.36). Aunque la tradición por motivos varios ha acentuado el carácter masculino de Dios, en un contexto poético como este, rescatar la imagen de la madre es sumamente importante, pues ella representa en la cultura la entrega tierna e incondicional al hijo. Enriquecer a Dios con ambos roles pone de manifiesto la solicitud de su amor:

Tú te inclinas

Te abajas hasta el nivel de mi boca casi muda...

Me escuchas enseguida, cuando te invoco.

La imagen es sumamente gráfica: existe una diferencia de alturas entre el padre y el hijo, que es salvada por la atracción amorosa del uno por el otro. La vulnerabilidad del sujeto, de este modo, encuentra una respuesta sanadora en la relación filial con Dios Padre que irrumpe en el gran miedo existencial: "En el centro de mi ser oigo la voz: / «Tú eres mi hijo amado en quien me complazco»". La fragilidad se sigue manifestando en la tibia sensibilidad del hablante al momento de orar: "¿Qué pasa?... ¡Parece que no brota ningún grito / desde mi alma seca y sedienta". Sin embargo, confiando en la existencia de un Dios Padre que le habla, el hablante toma el riesgo de seguir buscando la intimidad con Él, a pesar de su insensibilidad aparente a la realidad sobrenatural:

Me dices en lo secreto: Yo sé que me llamas,

Aunque tu corazón parece estar dormido,

Escucho la oración que no dices.

Para terminar el análisis de este poema, es necesario resaltar un elemento importante que concierne a la fragilidad humana. Aunque sin duda la imagen de Dios Padre es protagónica, también 
aparecen a lo largo de toda la enunciación tanto el Hijo como el Espíritu Santo. Este último cumple un rol fundamental, porque es quien inspira la oración genuina: "Tu Espíritu, Señor, la inspira en el recinto del silencio, / con gemidos inenarrables". Bajo esta realidad subyace la idea de que la intimidad dialógica con Dios no se establece según el capricho humano, sino que es Él quien en su rol de creador ha tomado la iniciativa: "Desde toda la eternidad su voz me llama y me da vida". Por tanto, la relación con la persona divina no es fruto de un voluntarismo del sujeto, sino de la inalterable voluntad de Dios. La omnipotencia divina se ha inclinado hacia la fragilidad humana gratuitamente, y es quien educa al sujeto para un diálogo propicio no necesariamente sensible:

«Que mi grito llegue hasta Ti, Señor... No me escondas tu rostro».

Me invitas a reconocer la voz que viene desde las entrañas.

El final del poema admite que solo la inspiración del Espíritu Santo es capaz de crear la auténtica intimidad, mientras el hombre fracasa en el intento de establecer la oración por sus propios medios:

\footnotetext{
Lo que hago, lo que pienso, lo que pasa ... me aturden; Son unos parlantes indiscretos, a todo volumen, Que no dejan escuchar al amigo vecino.

Ahora, «ven en mi auxilio;

Apresúrate, Señor, a socorrerme»
}

\section{Conclusiones}

Del anterior análisis se desprenden tres ideas centrales que verifican la hipótesis inicial de esta investigación. La primera de ellas consiste en el carácter conversacional que se deriva de las formalidades poéticas del corpus de Gumucio: desde la actitud apostrófica, pasando por el modo de versificación hasta el uso del lenguaje y vocabulario, todo apunta a la construcción de una lírica dialógica. Esta se desprende de la autopercepción de fragilidad del hablante, quien reconoce el no poseer la verdad absoluta del poema y se complementa con la palabra de Dios, el interlocutor. En segundo lugar, la experiencia de la incertidumbre frente a la Persona divina aparece como un factor común a la totalidad del corpus, debido a la limitada capacidad de entendimiento frente al mundo sobrenatural. Como consecuencia a la incertidumbre se propone el salto de riesgo del hablante, que se aventura a confiar su fragilidad a Dios sin certezas empíricas. Por último, las elecciones léxicas que se hacen en los poemas son significativas a nivel semántico: metáforas acerca de la infancia, recursos de la naturaleza y expresiones no concluyentes ("tal vez", "no sé") apuntan de forma unánime a la fragilidad de quien enuncia.

El ejercicio que se ha realizado en esta investigación es extrapolable a otros tantos poemas de Esteban Gumucio que no formaron en esta ocasión parte del corpus. La fragilidad de la persona humana pareciera ser uno de los principios que el autor postula en su poesía, y que tiene mucho que decir a las preguntas antropológicas y de trascendencia de la actualidad. 


\section{Referencias Bibliográficas}

Blume, J., y Espinoza, F. (2021, Abril 20). Una fe dos miradas [E-mail para M. I. Manterola Dominguez].

Escárate Cortés, P. (1999). Bienaventurados los mansos. Entrevista con Esteban Gumucio, SS.CC. Mensaje, 48, 37-39. https://bit.ly/3H4Ylh6

Gumucio, E. (2005). Poemas. Fundación Coudrin.

Meis, A (2010). Edith Stein y Tomás de Aquino: repercusión sobre la cuestión de la mujer. Teología y Vida, 51, 9-37. http://dx.doi.org/10.4067/S0049-34492010000100002

Onell, R. (2010). Poemas. Esteban Gumucio SSCC. Literatura y Lingüística, 21, 135137. https://doi.org/10.29344/0717621X.21.139

Valenzuela Damilano, M. (2013). Esteban Gumucio Vives SSCC. Espiritualidad de un religioso sacerdote. (Tesis de Doctorado). Pontificia Università Gregoriana. https://bit.ly/3klekDa

\section{Para citar este artículo bajo norma APA 7a ed.}

Manterola Domínguez, M. I. (2021). "Ser mano de niño afirmada en Ti": la

fragilidad de la persona humana en la poesía religiosa de Esteban

Gumucio SSCC. Cuadernos de teología - Universidad Católica del Norte (En

línea), 13, e5067. https://doi.org/10.22199/issn.0719-8175-2021-5067

doi

Copyright del articulo: @2021 María Manterola

(cc) BY

Este es un artículo de acceso abierto, bajo licencia Creative Commons BY 4.0. 